3

\title{
CHILE: EL AÑO EN QUE NOS QUEDAMOS EN CASA ${ }^{1}$
}

DOI: https://doi.org/10.7764/obitel.21.S.5

\begin{abstract}
Autores:
Pablo Julio Pohlhammer (https://orcid.org/0000-0003-1387-4463),

Constanza Mujica (https://orcid.org/0000-0001-8003-1576), Francisco J. Fernández Medina ${ }^{2}$ (https://orcid.org/0000-0001-6146-0375)

Alejandro Bruna ${ }^{3}$ (https://orcid.org/0000-0002-1217-2833)
\end{abstract}

\section{Equipo: Angela Godoy}

\section{Introducción}

De no haber mediado la pandemia de COVID-19, es probable que 2020 hubiese sido un año en que la televisión chilena estaría marcada por las manifestaciones sociales y eventos políticos iniciados en octubre de 2019. En las semanas que siguieron al comienzo del estallido fue notoria la baja en la actividad publicitaria. Los anunciantes retiraron su avisaje frente a la perplejidad. Los hechos eran demasiado significativos como para que los mensajes fueran los mismos que antes, pero adaptarlos probablemente hubiera sido a ser leído como frivolidad o aprovechamiento oportunista. La respuesta fue el silencio. Se esperaba que en marzo, tras el retorno del verano, las manifestaciones volvieran a cobrar fuerza, pero llegó la pandemia.

Como en casi todos los otros países, los esfuerzos por combatir la pandemia impusieron serias restricciones a la movilidad de las perso-

1 Los autores quieren expresar su agradecimiento hacia la empresa Kantar IBOPE Media Chile, sin cuya invaluable colaboración este trabajo no sería posible.

2 Profesores asociados de la Facultad de Comunicaciones de la Pontificia Universidad Católica de Chile.

3 Estudiante del Doctorado de Ciencias de la Comunicación, Facultad de Comunicaciones de la Pontificia Universidad Católica de Chile. 
nas, y muchos debieron permanecer por largos períodos en sus hogares, sin salir a trabajar, estudiar o simplemente divertirse. La presencia de más personas y más tiempo en el hogar aumentó la necesidad y disponibilidad de tiempo para consumir contenidos audiovisuales. Aumentó la audiencia de la televisión abierta y de pago que venían bajando; dejaron de caer las suscripciones a la televisión de pago y aumentaron las suscripciones a VoD; se duplicó el crecimiento del internet fijo domiciliario y también se aceleró el crecimiento de las conexiones móviles; y el tráfico de datos creció el triple de los que había crecido el año anterior. A excepción de las salas de cine, todas las pantallas estuvieron encendidas.

Sin embargo, así como el consumo creció, la producción se desplomó. La exhibición de ficción nacional de estreno cayó casi a la mitad debido a las dificultades de producción impuestas por las restricciones sanitarias y la reposición de títulos nacionales ya exhibidos fue lo que caracterizó a las pantallas de televisión abierta.

\section{EI Contexto Audiovisual de Chile en 2020}

\subsection{La televisión abierta en Chile}

\section{Cuadro 1: Canales nacionales de televisión abierta en Chile}

\begin{tabular}{|c|c|}
\hline Canales privados (6) & Canales públicos (1) \\
\hline $\begin{array}{l}\text { Canal 13: Grupo Luksic (chileno) } \\
\text { Chilevisión: Viacom CBS . } \\
\text { La Red: Grupo Albavisión. } \\
\text { Mega: Grupo Bethia (chileno), Discovery Communications (27.5\%) } \\
\text { Telecanal: Pertenece a Inversiones Alfa Tres, (vinculado a Albavisión). } \\
\text { TV+: Media } 23 \text { (chileno), P. Universidad Católica de Valparaíso. }\end{array}$ & $\begin{array}{lr}\text { TVN, } & \text { con } \\
\text { financiamiento } & \text { sólo } \\
\text { publicitario. } & \end{array}$ \\
\hline & \\
\hline
\end{tabular}

Fuente: Obitel Chile

4 Durante 2020 y hasta el cierre de este informe Chilevisión seguía siendo propiedad de Warner Media, pero sólo restando para el traspaso de propiedad la aprobación de la Fiscalía Nacional Económica, la entidad encargada de la promoción y defensa de libre competencia en todos los mercados o sectores productivos de la economía chilena. 
Los resultados económicos de 2020 fueron disímiles para los principales canales. Por una parte, tanto Canal 13 como TVN, que habían tenido pérdidas por US\$9 millones y US\$17 millones en 2019, este año lograron tener cifras positivas como consecuencia de grandes esfuerzos de reestructuración y reducción de costos. Canal 13 logró utilidades por US\$9 millones y TVN por US\$1.1 millones. Especialmente significativo es el caso de TVN que desde 2013 no había logrado terminar el año sin pérdidas, lo que ponía en riesgo su continuidad sin una intervención y transformación como canal público.

Distinto fue el caso de CHV y Mega. CHV terminó 2020 con pérdidas de US\$6.7 millones que, sumadas a los US\$23 millones de 2019 y cifras negativas desde 2013, dan cuenta de lo frustrante que resultó la experiencia chilena para Warner Media desde que comprara el canal y hasta su venta. Por su parte, Mega tuvo pérdidas por casi US\$4 millones, pero más grave que eso, pasa a tener pérdidas tras un continuo deterioro de sus resultados desde 2016.

Gráfico 1: Rating y share TV por canal durante $2020^{5}$

\begin{tabular}{|l|c|c|c|}
\hline \multicolumn{1}{|c|}{ Canal } & $\begin{array}{c}\text { Rating } \\
\text { hogar }(\%)\end{array}$ & $\begin{array}{c}\text { Share en } \\
\text { Total TV (\%) }\end{array}$ & $\begin{array}{c}\text { Share en TV } \\
\text { abierta (\%) }\end{array}$ \\
\hline Canal 13 & 5,2 & 13,1 & 21,2 \\
\hline CHV & 6,0 & 14,9 & 24,3 \\
\hline Mega & 7,0 & 17,6 & 28,5 \\
\hline TVN & 4,7 & 11,7 & 18,9 \\
\hline TV+ & 0,6 & 1,5 & 2,5 \\
\hline La Red & 1,1 & 2,8 & 4,6 \\
\hline Telecanal ${ }^{6}$ & $\mathrm{n} / \mathrm{d}$ & $\mathrm{n} / \mathrm{d}$ & $\mathrm{n} / \mathrm{d}$ \\
\hline Suma TV abierta & 24,6 & 61,6 & - \\
\hline TV de pago & 15,3 & 38,4 & - \\
\hline TV abierta + TV pago & 39,9 & 100,0 & 100,0 \\
\hline
\end{tabular}

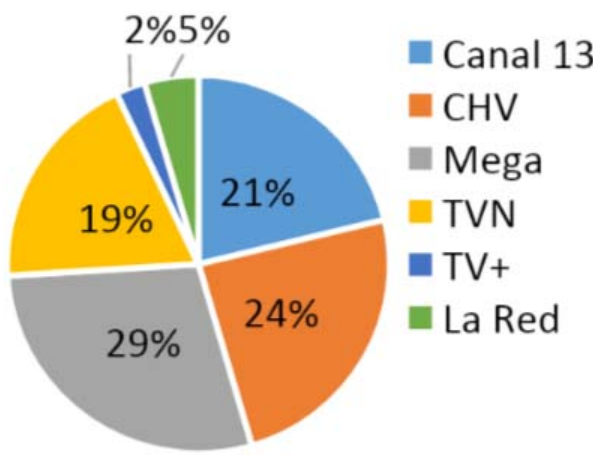

Fuente: Kantar IBOPE Media Chile - OBITEL Chile

5 Rating hogar tomado sobre las 24 horas del día, independientemente de los horarios de transmisión de los canales.

6 Desde 2019, la audiencia de Telecanal no está siendo medida. 
Mega sigue manteniendo el liderazgo de audiencia que conquistó en 2014, pero fue el único de los cuatro canales principales que redujo sus resultados de audiencia. Tomando como total esos cuatro canales, Mega logró su mayor participación entre los cuatro en 2017 con un $37 \%$ y desde entonces ha venido disminuyendo hasta un $31 \%$ en 2020. Sigue siendo el líder con ventaja, pero su participación ha ido disminuyendo, así como sus utilidades. Las posiciones de los otros canales se han mantenido estables.

Gráfico 2: Géneros y horas en la programación de TV durante 2020

\begin{tabular}{|c|c|c|c|}
\hline Géneros emitidos & $\begin{array}{l}\text { Horas de } \\
\text { exhibición } 7\end{array}$ & $\begin{array}{c}\% \\
\text { Tiempo }\end{array}$ & $\begin{array}{c}\% \\
\text { Audiencia }\end{array}$ \\
\hline Ficción & $10.980: 00$ & $24,2 \%$ & $38,8 \%$ \\
\hline Información & $13.235: 55$ & $29,2 \%$ & $31,3 \%$ \\
\hline Espectáculos & $9.381: 45$ & $20,7 \%$ & $8,8 \%$ \\
\hline Servicios & $7.184: 15$ & $15,8 \%$ & $6,2 \%$ \\
\hline Deportes & $402: 10$ & $0,9 \%$ & $0,5 \%$ \\
\hline Otros & $4.177: 10$ & $9,2 \%$ & $14,3 \%$ \\
\hline Total $^{8}$ & $45.361: 15$ & $100 \%$ & $100 \%$ \\
\hline
\end{tabular}

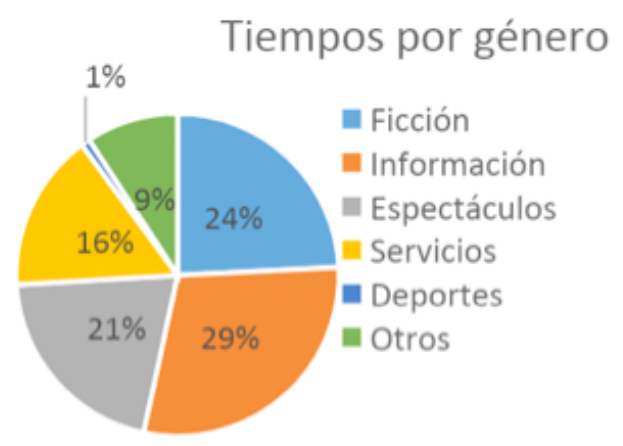

Fuente: Kantar IBOPE Media Chile - OBITEL Chile

Aunque a nivel agregado los tiempos de exhibición y preferencias de consumo tienden a ser relativamente estables, el efecto de la pandemia redundó en un aumento de los tiempos dedicados a la información, y a una de la participación de audiencia de la ficción similar a las anteriores. La mantención de la participación de la ficción debe leerse teniendo en mente que todas las fuentes de contenidos audiovisuales alternativos que crecieron, como plataformas o tv de pago, están más orientadas hacia la ficción. En 2020, las horas totales exhibidas en televisión abierta cayeron en 922 respecto de 2019. Sin

7 Para efectos de presentación, los tiempos en esta y las siguientes tablas están redondeados a cinco minutos.

8 En 2020, Telecanal no fue incluido en las mediciones de Kantar Ibope Media, por lo que no está considerado en este total 
embargo, aunque en todas las otras categorías hubo disminuciones, las horas dedicadas a la información aumentaron en 534.

\subsection{TV de pago y plataformas VoD en Chile}

Cuadro 2: Cadenas de televisión de pago en Chile 2020

\begin{tabular}{|l|c|c|c|}
\hline \multicolumn{4}{|c|}{10 canales de TV de pago más vistos en Chile } \\
\hline Canal & Género & Origen & Rating hogar \\
\hline 24 Horas & Información & Chile & 0,72 \\
\hline Fox Channel & Ficción & Extranjera & 0,68 \\
\hline $\begin{array}{l}\text { Cartoon } \\
\text { Network }\end{array}$ & Infantil & Extranjera & 0,67 \\
\hline Discovery Kids & Infantil & Extranjera & 0,53 \\
\hline CNN Chile & Información & Chile & 0,47 \\
\hline TNT & Ficción & Extranjera & 0,45 \\
\hline Disney Channel & Infantil & Extranjera & 0,41 \\
\hline AXN & Ficción & Extranjera & 0,40 \\
\hline Disney Junior & Infantil & Extranjera & 0,35 \\
\hline Discovery H\&H & Información & Extranjera & 0,35 \\
\hline
\end{tabular}

Fuente: Kantar IBOPE Media Chile

\section{Cuadro 3: El VoD en Chile}

\section{Principales plataformas de VoD activas en 2020}

Cinco plataformas más populares entre quienes han contratado al menos una: Netflix, Prime Video, HBO, Disney +, CDF Estadio VoD de operadores de cable: Movistar Play, VTR+, Claro Video, Entel Go, DirecTV Go

Otras plataformas populares: Apple TV, Onda Media, 13Now, Cining, Punto Ticket, CNTV Play

Fuente: para las cinco más populares, estudio Streaming en Chile de la agencia Jelly; resto, OBITEL Chile 


\subsection{Productoras independientes de ficción televisiva}

La última gran crisis económica que afectó a Chile, la crisis Subprime, provocó que durante 2008 y 2009 tuvieran que cerrar buena parte de las principales productoras independientes que trabajaban para la televisión, como Cine Cien, Roos Film, Nueva Imagen, Cubo Negro, Buen Puerto, Cinembargo, Calypso, entre otras. La razón es que las productoras suelen ser organizaciones con poco capital de trabajo y que dependen de la continuidad de los proyectos que van asumiendo. La industria se ha sofisticado y las principales productoras actuales, como Parox, DDRío, AGTV o Fábula TV se encuentran mejor estructuradas y diversificadas. Pero la detención o postergación de proyectos durante 2020 y 2021 ha disminuido fuertemente el volumen de producción y es posible que algunas de estas u otras de menor tamaño tengan dificultades para sostenerse.

\subsection{Fuentes de financiamiento del sector audiovisual}

A pesar de la continua declinación de la televisión abierta como destino de la inversión publicitaria, ésta sigue siendo su principal fuente de financiamiento y, con ella, de la ficción televisiva. La televisión de pago, que tiene otras fuentes de financiamiento, no es relevante para estos efectos ya que la televisión de pago no produce ficción en Chile.

Hasta septiembre, la inversión publicitaria en televisión abierta había tenido un comportamiento muy similar al de 2018. Sin embargo, en el último cuarto del año, tradicionalmente el de mayor facturación, la inversión se desplomó como consecuencia de las convulsiones sociales que se comenzaron a vivir en Chile a partir de octubre. La inversión publicitaria continuó deprimida en el primer mes de 2020, pero cuando en febrero ya parecía recobrar la normalidad, el arribo de la pandemia la volvió a golpear y siguió cayendo hasta abril. A partir de mayo comenzó una lenta recuperación que sólo a partir de septiembre recobró niveles comparables con los de 2018. Con todo, la 
inversión publicitaria en televisión abierta terminó 2020 en US\$227 millones, un $20 \%$ menos que en 2019 , un $36 \%$ menos que en 2018 y un $63 \%$ menos que en 2011, en que alcanzó su máximo histórico (AAM, 2021 y ACHAP, 2012). En otras palabras, la televisión abierta y la ficción televisiva se están financiando con recursos similares a los del año 2000 en un país que, a valores nominales, casi ha triplicado su PIB per cápita en ese período.

A diferencia de los recursos publicitarios, el fondo del Consejo Nacional de Televisión, cuya finalidad es promover la televisión de calidad en distintos formatos, tuvo un muy significativo $45 \%$ de aumento respecto de 2019, alcanzado los $\$ 4.585$ millones. Sin embargo, a pesar de aumento, este fondo equivale sólo a un 2,5\% de los ingresos publicitarios, por lo que no logra compensar la disminución de presupuestos de la televisión abierta.

A diferencia de las fuentes de financiamiento tradicionales, es en el terreno de las plataformas de $\mathrm{VoD}$ donde generan expectativas de nuevas fuentes de financiamiento para la ficción. Aunque se trate de casos puntuales, las cuatro series nacionales estrenadas en Prime Video en 2020, dos en coproducción, muestran que se trata de un camino incipiente pero factible para el desarrollo de la ficción seriada nacional.

\subsection{Políticas de comunicación}

El cierre de los colegios por la pandemia y la consecuente presencia permanente de los niños en el hogar puso de manifiesto algo que se arrastra por años: la reducción de la programación dirigida específicamente a los niños en la televisión abierta chilena. De acuerdo con la información elaborada para informes Obitel anteriores, la suma de los contenidos de series animadas, educativos e instruccionales sumó en 2019 un 1,3\% del tiempo de pantalla. Una década antes, en 2009 , esta cifra era de un 9,4\%. La diferencia se explica por la casi desaparición de las series animadas. 
La televisión de pago ofrece múltiples opciones de contenidos de entretención para los niños, pero pocos de carácter educativo, por lo que el problema afectaba a los hogares con y sin acceso a la televisión de pago. La respuesta a esta carencia fue la creación de la señal TV Educa Chile que empezó sus transmisiones el 27 de abril de 2020. Una experiencia educativa promovida por el conjunto de los canales de televisión y apoyada por en CNTV y el Ministerio de Educación y otros colaboradores que pusieron gratuitamente sus contenidos a disposición de esta señal. Los contenidos fueron transmitidos a través de múltiples vías: canales de streaming, señales de televisión digital de los principales canales de televisión abierta y múltiples operadores de televisión de pago.

Esta experiencia motivó la proyección de otras iniciativas. A partir de un estudio realizado en 2019, en Consejo Nacional de Televisión (CNTV, 2019) evaluó que existía una deficiencia de oferta dirigida específicamente a los adultos mayores, a pesar de tratarse del grupo población con tiempos de consumo más elevado. La situación de encierro de la pandemia hizo patente la carencia. En Septiembre de 2020, el CNTV anunció para 2021 el lanzamiento de una nueva señal, TV Mayor, destinada a la tercera edad, destinada a llenar los vacíos de información educativa y de servicios destinada a esta población. De llegar a concretarse, TV Mayor no sería el primer canal segmentado, pero sí el primero de gran alcance y mayor ambición programática. Ya existe una experiencia iniciada en 2020, Vitalidad TV, pero llegando a un sector geográfico limitado. Es operado por la empresa de televisión por cable Mundo con presencia en las regiones de Valparaíso y Los Ríos. En anuncio de la creación de TV Mayor está hecho, pero no se ha informado de avances en el proyecto.

Si, como se mencionó, una de las vías de transmisión de TV Educa Chile fueron señales de TDT, el hecho que su plena implementación de está muy lejos de completarse. De acuerdo con la ley de televisión digital terrestre promulgada en 2014 por la entonces presidenta 
Michelle Bachelet, el apagón analógico debió ocurrir durante 2020. Sin embargo, en 2019 los canales de televisión lograron que fuera postergado hasta 2024. Si este plazo se cumple, habrán pasado 15 años entre la definición de la norma que se usaría en Chile (ISBD-Tb) y su plena implementación.

\subsection{Infraestructura de conectividad digital y móvil}

Las cuarentenas, confinamientos y limitaciones a la circulación aumentaron las necesidades de conexión de las personas desde sus hogares, ya sea para estudiar, trabajar o entretenerse. Esto se tradujo en un aumento de un $13 \%$ en la cantidad de viviendas con una conexión fija a internet $\mathrm{y}$, consecuencia de lo mismo tiempo, una disminución del 6\% en las conexiones en empresas. Ese aumento en hogares casi triplicó el crecimiento del año anterior y 2020 terminó el año con aproximadamente un $58 \%$ de las viviendas con una conexión fija a internet (Subtel, 2021b). En aumento no fue sólo en cantidad de conexiones fijas: a partir de marzo, el tráfico de datos en ellas en promedio en un 64\% respecto del mismo periodo del año anterior (Subtel, 2021d).

Aunque los crecimientos fueron menores que en la conectividad fija, el aumento en conexiones móviles $3 \mathrm{G}$ y $4 \mathrm{G}$, que son el 99\% de las conexiones móviles, creció en un 7\% entre diciembre de 2019 y diciembre de 2020, alcanzándose una tasa 104,7 conexiones por cada 100 habitantes (Subtel, 2021c) y un aumento en el tráfico de datos del $40 \%$. 


\section{Análisis del Año: La ficción de estreno nacional e iberoamerica- na en la TV abierta}

Tabla 1. Ficciones exhibidas en 2020

\begin{tabular}{|c|c|}
\hline TITULOS INÉDITOS NACIONALES - 12 & 3. Los 80: más que una moda (serie) \\
\hline Canal 13 & 4. Machos (telenovela) \\
\hline 1. Amor a la Catalán (telenovela) & 5. Pacto de Sangre (telenovela) \\
\hline 2. Helga y Flora (serie) & 6. Papi Ricky (telenovela) \\
\hline 3. Los Carcamales (serie) & 7. Soltera otra vez (telenovela) \\
\hline CHV & CHV \\
\hline 4. Gemelas Idénticas en Nada (telenovela) & 8. Lo que Callamos las Mujeres (unitario) \\
\hline 5. Héroes Invisibles (miniserie) & Mega \\
\hline Mega & 9. Amanda (telenovela) \\
\hline 6. 100 Días para Enamorarse (telenovela) & 10. Eres mi Tesoro (telenovela) \\
\hline 7. Dignidad (serie) & 11. Isla Paraíso (telenovela) \\
\hline 8. Historias de Cuarentena (serie) & 12. Papá a la Deriva (telenovela) \\
\hline 9. Verdades Ocultas (telenovela) & 13. Perdona Nuestros Pecados (telenovela) \\
\hline 10. Yo Soy Lorenzo (telenovela) & 14. Pituca sin Lucas (telenovela) \\
\hline TVN & 15. Pobre Gallo (telenovela) \\
\hline 11. Berko, el Arte de Callar (serie) & 16. Señores Papis (telenovela) \\
\hline 12. La Jauría (serie) & $\begin{array}{l}\text { 17. Te Doy la Vida (telenovela) } \\
\text { TVN }\end{array}$ \\
\hline TITULOS IMPORTADOS INÉDITOS - 13 & 18. Aquelarre (telenovela) \\
\hline Canal 13 & 19. Aquí Mando Yo (telenovela) \\
\hline 1. Luis Miguel La Serie (serie-EE. UU.-Hispano) & 20. Cuentos Chilenos (telefilm) \\
\hline CHV & 21. Dama y Obrero (telenovela) \\
\hline 2. Jesús (telenovela-Brasil) & 22. Dónde Está Elisa (telenovela) \\
\hline Mega & 23. El Circo de las Montini (telenovela) \\
\hline 3. El Otro Lado del Paraíso (telenovela-Brasil) & 24. El Día Menos Pensado (docudrama) \\
\hline 4. Nuevo Sol (telenovela-Brasil) & 25. La Canción de tu Vida (serie) \\
\hline 5. Orgullo y Pasión (telenovela-Brasil) & 26. La Chúcara (telenovela) \\
\hline TV+ & 27. Mea Culpa (docudrama) \\
\hline 6. Pecado Mortal (telenovela-Brasil) & TV+ \\
\hline 7. La Bruja (telenovela-Colombia) & 28. Familia Moderna (serie) \\
\hline 8. Decisiones (unitario-EE.UU.-Hispano) & 29. Infieles (serie) \\
\hline 9. Raphael de España (miniserie-España) & 30. Los Años Dorados (sitcom) \\
\hline La Red & La Red \\
\hline 10. Cita a Ciegas (telenovela-México) & 31. Tira (serie) \\
\hline 11. La Rosa de Guadalupe (serie-México) & TÍTULOS EXTRANJEROS REPOSICIONES - 19 \\
\hline 12. Rosario Tijeras (telenovela-México) & Canal 13 \\
\hline 13. Vencer el Miedo (telenovela-México) & $\begin{array}{l}\text { 1. Pablo Escobar el Patrón del Mal (serie-Colombia) } \\
\text { CHV }\end{array}$ \\
\hline TÍTULOS NACIONALES REPOSICIONES- 31 & 2. Victoria (telenovela-México) \\
\hline Canal 13 & Mega \\
\hline 1. Brujas (telenovela) & 3. Insensato Corazón (telenovela-Brasil) \\
\hline 2. Irreversible (serie) & \\
\hline
\end{tabular}




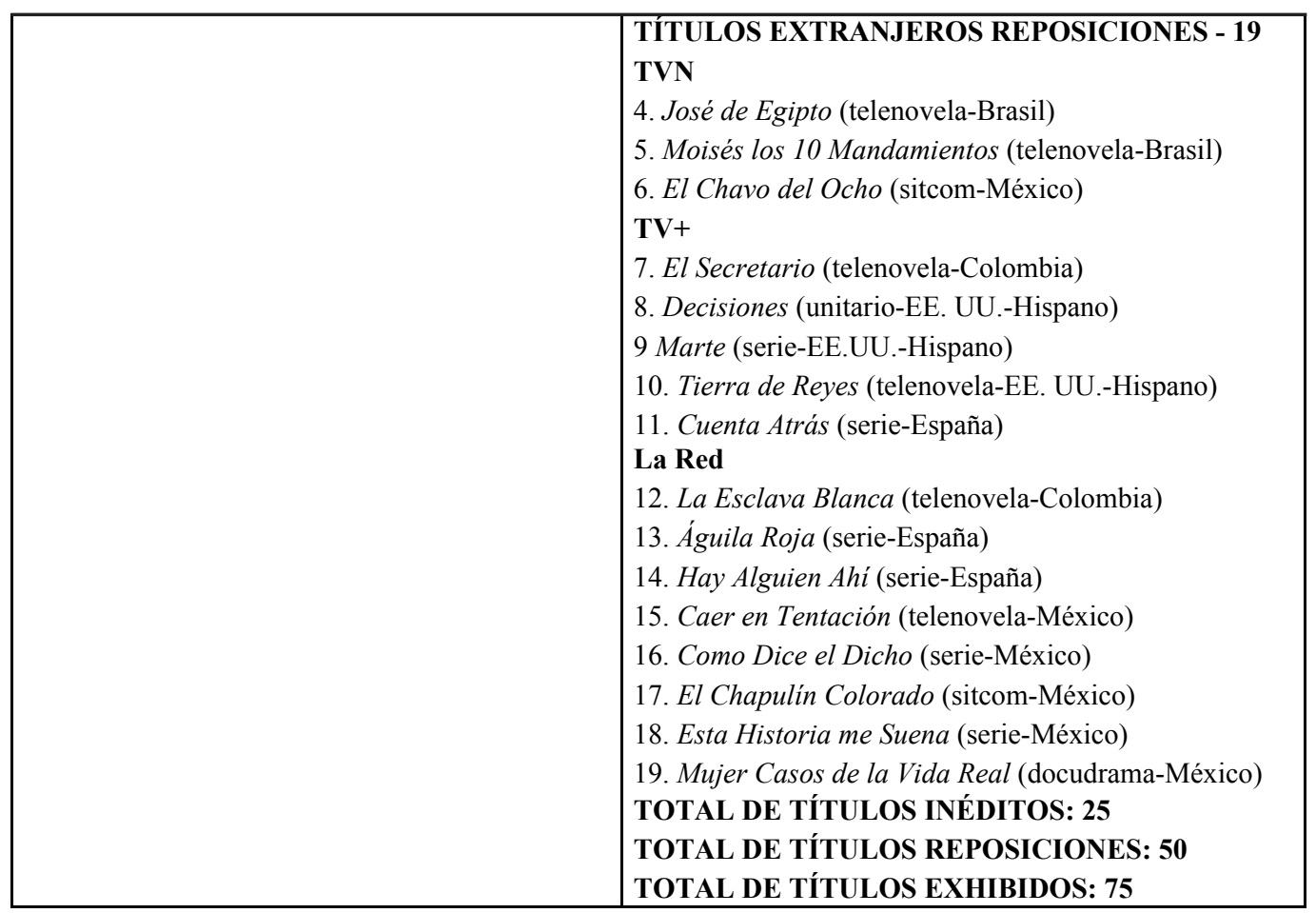

Fuente: Kantar IBOPE Media Chile - OBITEL Chile

Desde su irrupción en 2014, la ficción televisiva turca constituye un dato necesario para comprender el panorama televisivo chileno, ya que tanto en su rol en la programación como por sus formas de consumo, resulta casi indistinguible de la ficción televisiva iberoamericana y está distribuida en cinco canales de televisión. Además, en términos de ficción televisiva de estreno, su importancia es mayor que la de cualquier otro actor. Medida en tiempo, equivale a un $61 \%$ de las horas de estreno nacionales e iberoamericanas, y en términos de audiencia, alcanza a un $60 \%$ de lo que alcanzan éstas. ${ }^{9}$

No obstante la persistencia de la importancia del fenómeno turco, el hecho significativo durante 2020 fue el impacto de la pandemia de Covid-19 en la producción, programación y consumo televisivo, que empezó a sentirse desde el mes de marzo.

9 En términos absolutos, sus títulos, horas y número de episodios de estreno se redujeron aproximadamente a la mitad que en 2019, pero como se muestra más adelante, algo similar ocurrió con casi toda la ficción televisiva de estreno iberoamericana. 
Los cambios en tabla 1 , entre 2020 y 2019, dan una aproximación inmediata a lo ocurrido: la exhibición de títulos nacionales de estreno se contrajo, pasando de 17 a 12 títulos, siendo sólo 5 de éstos telenovelas, iniciadas todas en 2019, y el resto fueron formatos de menor duración. Sin embargo, la presencia de la ficción nacional puesta en pantalla, lejos de disminuir, aumento. La reposición de títulos exhibidos en años anteriores paso de 9 en 2019 a 31 durante 2020 .

En el ámbito iberoamericano, si bien la cantidad de títulos de estreno fue ligeramente menor a la de 2019 (13 versus 14), el aumento de reposiciones fue casi tan explosivo que el caso nacional, pasando de 11 en 2019 a 19 en 2020.

Tabla 2. Ficción de estreno en 2020: países de origen

\begin{tabular}{|c|c|c|c|c|c|c|}
\hline País & Títulos & $\%$ & $\begin{array}{l}\text { Capítulos/ } \\
\text { Episodios }\end{array}$ & $\%$ & Horas & $\%$ \\
\hline NACIONAL (total) & 12 & 48,0 & 504 & 35,5 & 274:00 & 27,6 \\
\hline PAÍSES OBITEL (total) & 13 & 52,0 & 914 & 64,5 & $719: 50$ & 72,4 \\
\hline Argentina & 0 & 0,0 & 0 & 0,0 & $0: 00$ & 0,0 \\
\hline Brasil & 5 & 20,0 & 451 & 31,8 & $349: 50$ & 35,2 \\
\hline Chile & 12 & 48,0 & 504 & 35,5 & $274: 00$ & 27,6 \\
\hline Colombia & 1 & 4,0 & 36 & 2,5 & $31: 20$ & 3,2 \\
\hline Ecuador & 0 & 0,0 & 0 & 0,0 & $0: 00$ & 0,0 \\
\hline España & 1 & 4,0 & 3 & 0,2 & $3: 00$ & 0,3 \\
\hline EE.UU. Hispano & 2 & 8,0 & 11 & 0,8 & $7: 50$ & 0,8 \\
\hline México & 4 & 16,0 & 413 & 29,1 & $327: 55$ & 33,0 \\
\hline Perú & 0 & 0,0 & 0 & 0,0 & $0: 00$ & 0,0 \\
\hline Portugal & 0 & 0,0 & 0 & 0,0 & $0: 00$ & 0,0 \\
\hline Uruguay & 0 & 0,0 & 0 & 0,0 & $0: 00$ & 0,0 \\
\hline Venezuela & 0 & 0,0 & 0 & 0,0 & $0: 00$ & 0,0 \\
\hline $\begin{array}{l}\text { COPRODUCCIONES } \\
\text { (Totales) }\end{array}$ & 0 & 0,0 & 0 & 0,0 & 0:00 & 0,0 \\
\hline Coproducciones Nacionales & 0 & 0,0 & 0 & 0,0 & $0: 00$ & 0,0 \\
\hline Coproducciones Países Obitel & 0 & 0,0 & 0 & 0,0 & $0: 00$ & 0,0 \\
\hline TOTAL & 25 & 100,0 & 1.418 & 100,0 & 993:55 & 100,0 \\
\hline
\end{tabular}

Fuente: Kantar IBOPE Media Chile - OBITEL Chile

La tabla 2 muestra la exhibición de estreno de ficción televisiva iberoamericana exhibida durante 2020. El panorama se completa 
teniendo a la vista los datos de la ficción televisiva turca exhibida en el mismo período: 7 títulos, 725 episodios y 556 horas. Este dato no puede omitirse ya que supera largamente en tiempo de pantalla a cualquier país de la región. Aunque su exhibición se distribuye en todos los horarios, salvo las mañanas, se diferencia de la nacional y la iberoamericana en que está menos concentrada en el prime time (30\%) y una mayor proporción se destina a las tardes y horario nocturno que las de otros orígenes, resultando notorio que la oferta en el horario nocturno es mayoritariamente de origen turco (65\%).

Focalizando la mirada en el ámbito Obitel, la caída en la ficción de estreno es la mayor que se observa desde que se edita este anuario: tanto la cantidad de episodios exhibidos en 2020 como las horas de emisión fueron un 56\% de las que habían sido en 2019. Sólo un país aumentó su presencia, aunque partía de una base anormalmente baja. Brasil, pasó de 2 a 5 títulos, aumentó sus episodios en un 94\% y las horas exhibidas en un $62 \%$. La contracara de eso la representó México, cuya presencia cayó a un 40\% de los títulos, un 49\% de los episodios y un $45 \%$ de las horas que tuvo en 2019 , representando casi un cuarto los episodios y horas un solo título: La Rosa de Guadalupe.

TABLA 3. Formatos de ficción nacional e iberoamericana

\begin{tabular}{|c|c|c|c|c|c|c|c|c|c|c|c|c|}
\hline \multirow{2}{*}{ Formato } & \multicolumn{6}{|c|}{ Nacionales } & \multicolumn{6}{|c|}{ Iberoamericanos } \\
\hline & Títulos & $\%$ & $\mathbf{C} / \mathbf{E}$ & $\%$ & $\mathbf{H}$ & $\%$ & Títulos & $\%$ & $\mathrm{C} / \mathrm{E}$ & $\%$ & $\mathbf{H}$ & $\%$ \\
\hline \begin{tabular}{|l|} 
Telenovela \\
\end{tabular} & 5 & 41,7 & 435 & 86,3 & $224: 55$ & 82,1 & 9 & 69,2 & 795 & 87,0 & 632:00 & 87,8 \\
\hline Serie & 6 & 50,0 & 65 & 12,9 & $44: 35$ & 16,3 & 1 & 7,7 & 5 & 0,5 & $3: 50$ & 0,5 \\
\hline Miniserie & 1 & 8,3 & 4 & 0,8 & $4: 30$ & 1,6 & 1 & 7,7 & 3 & 0,3 & $3: 00$ & 0,4 \\
\hline Telefilm & 0 & 0,0 & 0 & 0,0 & $0: 00$ & 0,0 & 0 & 0,0 & 0 & 0,0 & $0: 00$ & 0,0 \\
\hline Unitario & 0 & 0,0 & 0 & 0,0 & $0: 00$ & 0,0 & 2 & 15,4 & 111 & 12,1 & $81: 05$ & 11,3 \\
\hline Docudrama & 0 & 0,0 & 0 & 0,0 & $0: 00$ & 0,0 & 0 & 0,0 & 0 & 0,0 & $0: 00$ & 0,0 \\
\hline Otros & 0 & 0,0 & 0 & 0,0 & $0: 00$ & 0,0 & 0 & 0,0 & 0 & 0,0 & $0: 00$ & 0,0 \\
\hline Total & 12 & 100,0 & 504 & 100,0 & \begin{tabular}{|l|}
$274: 00$ \\
\end{tabular} & 100,0 & 13 & 100,0 & 914 & 100,0 & \begin{tabular}{|l|}
$719: 50$ \\
\end{tabular} & 100,0 \\
\hline
\end{tabular}

Fuente: Kantar IBOPE Media Chile - OBITEL Chile 
La tabla 3, al compararla con la del año anterior, muestra que, en los formatos distintos a la telenovela, la ficción de estreno nacional no varió significativamente. Una razón es que los tiempos entre producción y exhibición de series y miniseries son mayores que en las telenovelas, por lo que los efectos de detención de los rodajes son más rezagados. Sin embargo, al ser la telenovela el género que predominante en la ficción chilena, que en un año de baja producción como 2020 concentró el 82\% del tiempo de pantalla, una caída en ella arrastra consigo a las cifras totales. En efecto, las horas exhibidas de telenovelas nacionales de estreno cayeron un 67\% respecto de 2019.

Aunque 2020 es un año anómalo como para constatar tendencias, la ausencia de otros formatos es algo que se viene observando en los últimos años y pareciera que la exploración de formatos en televisión tiende a estar fuera de la ficción y que para ésta, los creadores tienen la mirada más puesta en las oportunidades que presentan las plataformas.

TABLA 4: 10 Títulos más vistos en la televisión abierta

\begin{tabular}{|c|c|c|c|c|c|c|c|c|}
\hline \multicolumn{2}{|r|}{ Título } & \multirow{2}{*}{$\begin{array}{l}\text { Canal } \\
\text { Mega } \\
\end{array}$} & \multirow{2}{*}{\begin{tabular}{|c|} 
Productora \\
Chilefilms (CL) \\
\end{tabular}} & \multirow{2}{*}{$\begin{array}{l}\text { Formato/género } \\
\text { Telenovela/Drama }\end{array}$} & \multirow{2}{*}{$\begin{array}{c}\begin{array}{c}\text { No. de } \\
\text { cap/ep } \\
\text { en } 2020\end{array} \\
152^{* *} \\
\end{array}$} & \multirow{2}{*}{$\begin{array}{c}\begin{array}{c}\text { Franja } \\
\text { horaria }\end{array} \\
\text { Tarde } \\
\end{array}$} & \multirow{2}{*}{$\begin{array}{c}\text { Rating } \\
19,4 \\
\end{array}$} & \multirow{2}{*}{$\begin{array}{c}\text { Share } \\
53,8\end{array}$} \\
\hline 1 & Verdades Ocultas * & & & & & & & \\
\hline 2 & Yo Soy Lorenzo * & Mega & Mega (CL) & $\begin{array}{c}\text { Telenovela/Comedia } \\
\text { musical }\end{array}$ & $95 * *$ & Prime time & 17,0 & 40,9 \\
\hline 3 & $\begin{array}{l}\text { 100 Días para } \\
\text { Enamorarse * }\end{array}$ & Mega & $\begin{array}{c}\text { Mega + DDRío } \\
\text { Estudios (CL) }\end{array}$ & $\begin{array}{c}\text { Telenovela/Comedia } \\
\text { musical }\end{array}$ & $86^{* *}$ & Prime time & 15,8 & 35,3 \\
\hline 4 & $\begin{array}{l}\text { Historias de } \\
\text { Cuarentena } *\end{array}$ & Mega & Mega (CL) & Serie/Drama & $36^{* *}$ & Prime time & 11,4 & 28,4 \\
\hline 5 & $\begin{array}{l}\text { El Otro Lado del } \\
\text { Paraíso }\end{array}$ & Mega & Globo (BR) & Telenovela/Drama & $22 * *$ & Tarde & 10,7 & 38,4 \\
\hline 6 & Nuevo Sol & Mega & Globo (BR) & Telenovela/Drama & $127 * *$ & Tarde & 10,4 & 31,4 \\
\hline 7 & Los Carcamales * & Canal 13 & Kuarzo (CL) & Serie/Comedia & $1 * *$ & Prime time & 9,8 & 23,7 \\
\hline 8 & $\begin{array}{l}\text { Gemelas Idénticas } \\
\text { en Nada* }\end{array}$ & $\mathrm{CHV}$ & Parox (CL) & $\begin{array}{c}\text { Telenovela/Comedia } \\
\text { dramática }\end{array}$ & $73 * *$ & Prime time & 9,6 & 21,7 \\
\hline 9 & La Jauría* & TVN & $\begin{array}{l}\text { Fábula (CL), } \\
\text { Fremantle } \\
\text { (UK), Kapow } \\
\text { (AR) }\end{array}$ & Serie/Drama & 8 & Prime time & 9,3 & 21,0 \\
\hline 10 & $\begin{array}{l}\text { Héroes Invisibles } \\
*\end{array}$ & $\mathrm{CHV}$ & $\begin{array}{c}\text { Parox (CL), } \\
\text { Kaiho Republic } \\
\text { (FI), Yleisradio } \\
\text { (FI) }\end{array}$ & Miniserie/Drama & 4 & Prime time & 9,0 & 23,5 \\
\hline \multicolumn{4}{|c|}{ Total de producciones nacionales: 8} & \multicolumn{5}{|c|}{ Guiones originales extranjeros: 5} \\
\hline \multicolumn{4}{|c|}{$80 \%$} & \multicolumn{5}{|c|}{$50 \%$} \\
\hline
\end{tabular}

Fuente: Kantar IBOPE Media Chile - OBITEL Chile

(*): Indica producción nacional, (**): Su emisión comenzó en 2019 o pasó a 2021

10 Fue realizada en coproducción con Finlandia. 
A pesar del freno que 2020 representó para la exhibición de títulos nacionales de estreno, la ficción nacional pareciera haberse consolidado en la recuperación de las preferencias del público local. Hasta antes de la irrupción turca, sólo excepcionalmente un título extranjero lograba situarse entre los 10 más visto. Luego la industria entró en una profunda crisis y la producción nacional fue parcialmente desplazada por la producción iberoamericana. Sin embargo, desde 2017 se observa que ocho de los diez títulos más vistos corresponden a producciones nacionales. Cabe destacar que el décimo título de esta lista, Héroes Invisibles, corresponde a una coproducción entre Chile y Finlandia.

Por otra parte, si en esta lista de los 10 títulos más visto se diera cabida también a la ficción turca, tres telenovelas de ese origen deberían ser incluidas, desplazando de ella a tres títulos nacionales.

\section{TABLA 4A: Los 10 títulos nacionales más vistos en la televisión abierta}

\begin{tabular}{|c|c|c|c|c|c|c|c|c|}
\hline & Título & Canal & Productora & Formato/género & $\begin{array}{l}\text { No. de } \\
\text { cap/ep (en }\end{array}$ & $\begin{array}{l}\text { Franja } \\
\text { horaria }\end{array}$ & Rating & Share \\
\hline 1 & $\begin{array}{c}\text { Verdades } \\
\text { Ocultas }\end{array}$ & Mega & Chilefilms (CL) & Telenovela/Drama & $152 *$ & Tarde & 19,4 & 53,8 \\
\hline 2 & $\begin{array}{c}\text { Yo Soy } \\
\text { Lorenzo } \\
\end{array}$ & Mega & Mega (CL) & $\begin{array}{c}\text { Telenovela/Comedia } \\
\text { musical }\end{array}$ & $95^{*}$ & Prime time & 17,0 & 40,9 \\
\hline 3 & $\begin{array}{c}100 \text { Días } \\
\text { para } \\
\text { Enamorarse }\end{array}$ & Mega & $\begin{array}{l}\text { Mega + DDRío } \\
\text { Estudios (CL) }\end{array}$ & $\begin{array}{l}\text { Telenovela/Comedia } \\
\text { musical }\end{array}$ & $86^{*}$ & Prime time & 15,8 & 35,3 \\
\hline 4 & $\begin{array}{l}\text { Historias de } \\
\text { Cuarentena }\end{array}$ & Mega & Mega (CL) & Serie/Drama & $36^{*}$ & Prime time & 11,4 & 28,4 \\
\hline 5 & $\begin{array}{c}\text { Los } \\
\text { Carcamales } \\
\end{array}$ & $\begin{array}{c}\text { Canal } \\
13 \\
\end{array}$ & Kuarzo (CL) & Serie/Comedia & $1^{*}$ & Prime time & 9,8 & 23,7 \\
\hline 6 & $\begin{array}{c}\text { Gemelas } \\
\text { Idénticas en } \\
\text { Nada }\end{array}$ & $\mathrm{CHV}$ & Parox (CL) & $\begin{array}{c}\text { Telenovela/Comedia } \\
\text { dramática }\end{array}$ & $73 *$ & Prime time & 9,6 & 21,7 \\
\hline 7 & La Jauría & TVN & $\begin{array}{c}\text { Fábula (CL), Fremantle } \\
\text { (UK), Kapow (AR) }\end{array}$ & Serie/Drama & 8 & Prime time & 9,3 & 21,0 \\
\hline 8 & $\begin{array}{l}\text { Héroes } \\
\text { Invisibles }\end{array}$ & $\mathrm{CHV}$ & $\begin{array}{c}\text { Parox (CL), Kaiho } \\
\text { Republic (FI), } \\
\text { Yleisradio (FI) }\end{array}$ & Miniserie/Drama & 4 & Prime time & 9,0 & 23,5 \\
\hline 9 & $\begin{array}{l}\text { Helga } y \\
\text { Flora }\end{array}$ & $\begin{array}{c}\text { Canal } \\
13\end{array}$ & Suricato (CL) & Serie/Drama & 10 & Nocturno & 5,9 & 18,4 \\
\hline 10 & $\begin{array}{c}\text { Amor a la } \\
\text { Catalán } \\
\end{array}$ & $\begin{array}{c}\text { Canal } \\
13 \\
\end{array}$ & AGTV (CL) & $\begin{array}{c}\text { Telenovela/Comedia } \\
\text { dramática } \\
\end{array}$ & $29 *$ & Prime time & 5,8 & 14,3 \\
\hline \multicolumn{4}{|c|}{ Total de producciones nacionales: 10} & \multicolumn{5}{|c|}{ Guiones originales extranjeros: 3} \\
\hline \multicolumn{4}{|c|}{$100 \%$} & \multicolumn{5}{|c|}{$30 \%$} \\
\hline
\end{tabular}

Fuente: Kantar IBOPE Media Chile - OBITEL Chile

(*): Su emisión comenzó en 2019 o pasó a 2021 
La diferencia en esta recuperación del predominio nacional está en los actores. Hasta antes de la irrupción turca, los actores dominantes eran Canal 13 y TVN. Tras la recuperación, el predominio absoluto corresponde a Mega, ocupando los cuatro primeros lugares. Los Top 10 nacionales permitieron la entrada de dos producciones de Canal 13, pero cuyos niveles de audiencia son significativamente menores que los de la tabla original.

Cabe destacar que el único título de TVN en la lista de los Top 10, La Jauría, no corresponde a una producción tradicional de su área dramática, sino coproducción para Amazon, estrenada casi simultáneamente en esa plataforma y en televisión abierta.

TABLA 5: Perfil de audiencia de los 10 títulos más vistos: sexo, edad, nivel socioeconómico

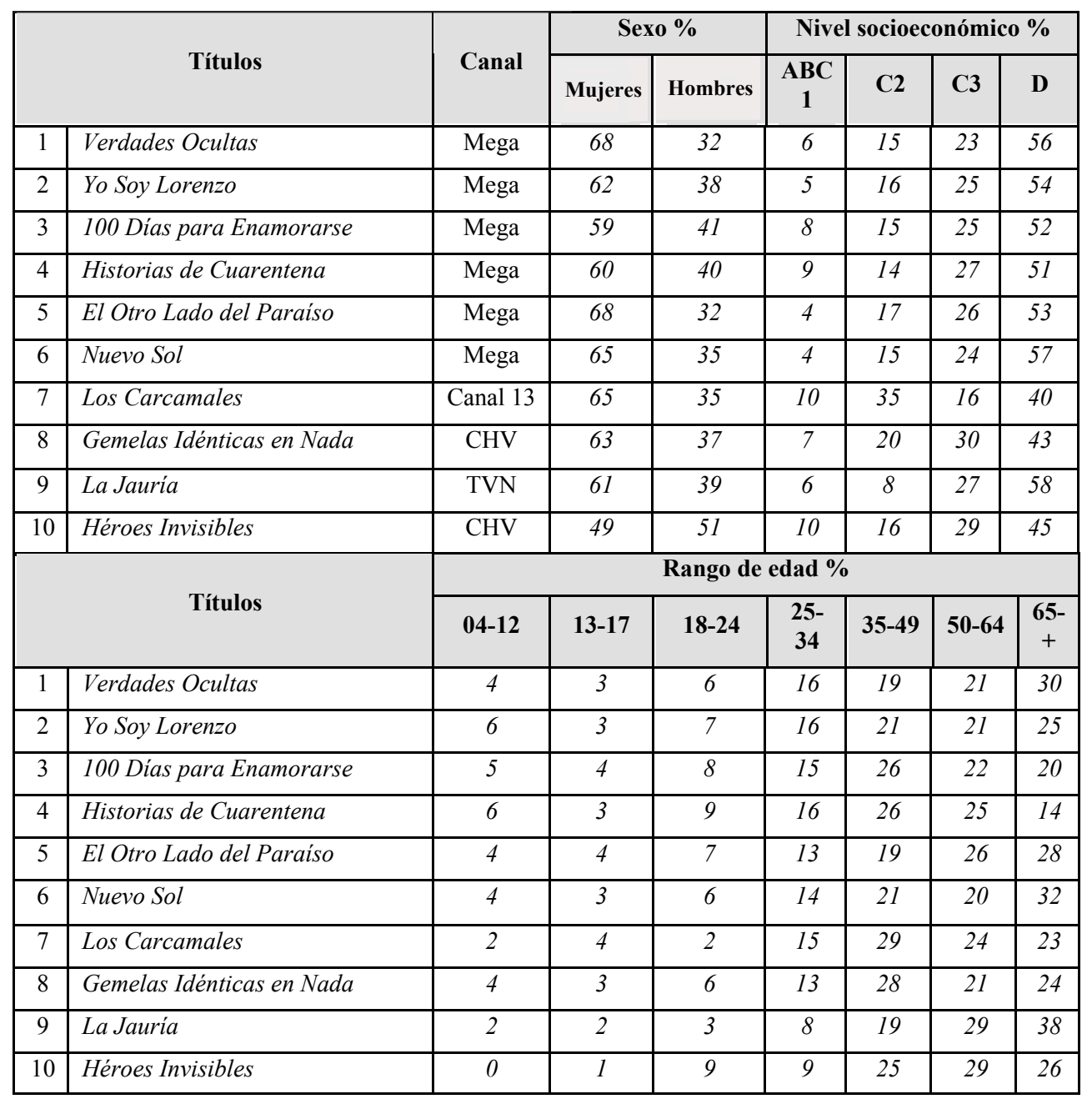

Fuente: Kantar IBOPE Media Chile, OBITEL Chile 
En los perfiles de audiencia de los Top 10 de este año se verifican los comportamientos habituales: el público de la ficción televisiva más vista es marcadamente femenino, a pesar de situarse en horarios en que la presencia en el hogar es transversal y, especialmente significativo, en un año en que, debido a los largos confinamientos a causa de la pandemia, hubo una mayor presencia en el hogar de todos sus miembros. La notable excepción a este patrón recurrente la marcó la coproducción chileno-finesa Héroes Invisibles, cuyo público fue masculino en una proporción mayor que la presente en la población.

\section{Monitoreo VoD 2020}

\subsection{Mercado de plataformas de VoD}

Aunque las plataformas pagadas de $\mathrm{VoD}$ han ido gradualmente penetrando en los hogares chilenos en los últimos años, 2020 representa una anomalía por las mismas razones que en buena parte del mundo. La pandemia de Covid-19, ya sea por cuarentenas o mayores restricciones a la circulación impuestas por las autoridades, llevaron a que los ciudadanos permanecieran más tiempo en los hogares, trayendo con ello, entre otras cosas, un mayor consumo VoD.

Netflix es la plataforma más popular y fue la primera en alcanzar una presencia significativa en Chile. ${ }^{10}$ Sin embargo, está lejos de ser la única y de ser contratada de modo exclusivo. Un estudio publicado en enero de 2021 indica que, entre quienes estuvieron suscritos al menos a un servicio de streaming durante el último año, un $41,9 \%$ está suscrito sólo a uno; un 30,1\% a dos; un 15,4\% a tres; 9,3\% entre 4 y 6 ; y un $3,3 \%$ dejó de estar suscrito. ${ }^{11}$

El mismo estudio muestra que, luego de Netflix, presente en un $88,7 \%$ de los hogares con al menos un servicio de streaming, en

10 El estudio Chile 3D de GfK Adimark arrojó para Netflix una penetración del 35\% de los hogares en su versión de septiembre de 2018 y de $51 \%$ en mayo de 2020 .

11 Streaming en Chile: la batalla que viene, realizado por la Agencia Jelly. Disponible en https://www.jelly.cl/streaming-en-chile/ 
orden de popularidad le siguen Prime Video (40\%), Disney+ (23,3\%), HBO GO (17,6\%), CDF Estadio (8,1\%) y otros (11,3\%). Lo destacable de la penetración de Disney+ es que en Chile fue lanzado recién en agosto de 2020 .

\subsection{Análisis del VoD en 2020: la ficción de estreno nacional e ibe- roamericana}

Tabla 6. Ficciones nacionales e iberoamericanas exhibidas en 2020 en sistemas de VoD

\begin{tabular}{|c|c|c|}
\hline $\begin{array}{l}\text { TÍTULOS } \\
\text { NACIONALES DE } \\
\text { ESTRENO }\end{array}$ & $\begin{array}{l}\text { TÍTULOS } \\
\text { IBEROAMERICANOS DE } \\
\text { ESTRENO }\end{array}$ & COPRODUCCIONES \\
\hline $\begin{array}{l}\text { Prime Video } \\
\text { 01. El Presidente } \\
\text { (serie - Chile) } \\
\text { 02. La Jauría } \\
\text { (serie - Chile) }\end{array}$ & $\begin{array}{l}\text { Prime Video } \\
\text { 01. Caronte (serie - España) } \\
\text { 02. Desaparecidos } \\
\text { (serie - España) } \\
\text { 03. El Cid (serie - España) } \\
\text { 04. Pequeñas Coincidencias } \\
\text { (serie - España) } \\
\text { 05. Backdoor } \\
\text { (serie - México) } \\
\text { 06. Cómo Sobrevivir Soltero } \\
\text { (serie - México) } \\
\text { 07. De Brutas, Nada } \\
\text { (serie - México) } \\
\text { 08. El Candidato } \\
\text { (serie - México) } \\
\text { 09. Pan y Circo } \\
\text { (serie - México) } \\
\text { Claro } \\
\text { 10. Hijos de su Madre (serie } \\
\text { - México) } \\
\text { 11. R (serie -México) } \\
\text { Netflix } \\
\text { 12. Casi Feliz } \\
\text { (serie - Argentina) } \\
\text { 13. Puerta } 7 \\
\text { (serie - Argentina) } \\
\text { 14. Secreto Bien Guardado } \\
\text { (serie - Argentina) } \\
\text { 15. 3\% (serie - Brasil) } \\
\text { 16. Buenos Días Verónica } \\
\text { (serie - Brasil) }\end{array}$ & $\begin{array}{l}\text { Prime Video } \\
\text { 01. Dignidad } \\
\text { (serie - Chile, Alemania) } \\
\text { 02. Inés del Alma Mía } \\
\text { (serie - España y Chile) } \\
\text { Movistar } \\
\text { 03. Dime Quién Soy } \\
\text { (serie - España y EE.UU. } \\
\text { Hispanos) } \\
\text { Netflix } \\
\text { 04. Selena: la serie (serie } \\
\text { - México, EE.UU. } \\
\text { Hispanos) } \\
\text { 05. Alguien tiene que } \\
\text { Morir (miniserie - } \\
\text { España, México) } \\
\text { 06. White Lines } \\
\text { (serie - España, RU) }\end{array}$ \\
\hline
\end{tabular}




\begin{tabular}{|c|c|c|}
\hline $\begin{array}{l}\text { TÍTULOS } \\
\text { NACIONALES DE } \\
\text { ESTRENO }\end{array}$ & $\begin{array}{l}\text { TÍTULOS } \\
\text { IBEROAMERICANOS DE } \\
\text { ESTRENO }\end{array}$ & COPRODUCCIONES \\
\hline & $\begin{array}{l}\text { 17. Coisa Mais Linda } \\
\text { (serie - Brasil) } \\
\text { 18. El Reto del Beso } \\
\text { (serie - Brasil) } \\
\text { 19. Espectros (serie -Brasil) } \\
\text { 20. Omnisciente } \\
\text { (serie - Brasil) } \\
\text { 21. Reality Z (serie - Brasil) } \\
\text { 22. Amar y Vivir } \\
\text { (serie - Colombia) } \\
\text { 23. Chichipatos } \\
\text { (serie - Colombia) } \\
\text { 24. El Robo del Siglo } \\
\text { (serie - Colombia) } \\
\text { 25. La Reina de Indias y el } \\
\text { Conquistador } \\
\text { (serie - Colombia) } \\
\text { 26. La Reina del Flow } \\
\text { (telenovela - Colombia) } \\
\text { 27. La Venganza de Analia } \\
\text { (serie - Colombia) } \\
\text { 28. Siempre Bruja } \\
\text { (serie - Colombia) } \\
\text { 29. 100 Días para } \\
\text { Enamorarnos } \\
\text { (serie - EE.UU. hispanos) } \\
\text { 30. Enemigo Intimo } \\
\text { (serie - EE.UU. Hispanos) } \\
\text { 31. Esta mierda me supera } \\
\text { (serie - EE.UU. Hispanos) } \\
\text { 32. Falsa Identidad } \\
\text { (telenovela - EEUU) } \\
\text { 33. No Te Puedes Esconder } \\
\text { (serie - EEUU) } \\
\text { 34. El Desorden que Dejas } \\
\text { (serie - España) } \\
\text { 35. El Sabor de las } \\
\text { Margaritas } \\
\text { (miniserie - España) } \\
\text { 36. Elite (serie - España) } \\
\text { 37. La Casa de Papel } \\
\text { (serie - España) }\end{array}$ & \\
\hline
\end{tabular}




\begin{tabular}{|c|c|c|}
\hline $\begin{array}{l}\text { TÍTULOS } \\
\text { NACIONALES DE } \\
\text { ESTRENO }\end{array}$ & $\begin{array}{l}\text { TÍTULOS } \\
\text { IBEROAMERICANOS DE } \\
\text { ESTRENO }\end{array}$ & COPRODUCCIONES \\
\hline & $\begin{array}{l}\text { 38. La Valla (serie - España) } \\
\text { 39. Las Chicas del Cable } \\
\text { (serie - España) } \\
\text { 40. Los Favoritos de Midas } \\
\text { (miniserie - España) } \\
\text { 41. Perdida (serie - España) } \\
\text { 42. Toy Boy (serie - España) } \\
\text { 43. Valeria (serie - España) } \\
\text { 44. Vis a Vis (serie - España) } \\
\text { 45. Vivir Sin Permiso } \\
\text { (serie - España) } \\
\text { 46. Bolívar } \\
\text { (telenovela - México) } \\
\text { 47. Control Z } \\
\text { (serie - México) } \\
\text { 48. Desenfrenadas } \\
\text { (serie - México) } \\
\text { 49. Diablero (serie - México) } \\
\text { 50. El Dragón: El Regreso } \\
\text { de un Guerrero } \\
\text { (serie - México) } \\
\text { 51. Historia de un Crimen: } \\
\text { La Búsqueda } \\
\text { (miniserie - México) } \\
\text { 52. La Casa de las Flores } \\
\text { (serie - México) } \\
\text { 53. La Piloto } \\
\text { (serie - México) } \\
\text { 54. Monarca (serie - México) } \\
\text { 55. Narcos México } \\
\text { (serie - México) } \\
\text { 56. Oscuro Deseo } \\
\text { (serie - México) }\end{array}$ & \\
\hline Total: 2 & Total: 56 & Total: 6 \\
\hline
\end{tabular}

Fuente: Obitel Chile

Aunque en un primer momento la presencia de producciones latinoamericanas en las plataformas se limitaba a la exhibición de títu- 
los ya emitidos en televisión o el cine, gradualmente ha ido creciendo el número de títulos producidos especialmente para ellas o en alianza con canales de televisión. En el caso chileno, cabe desatacar que los cuatro títulos nacionales presentes se tratan de producciones para Prime Video, dos en coproducción con otros países.

A pesar de no tratarse de ficción seriada, debe mencionarse que en 2020 se estrenó en Netflix Nadie Sabe que Estoy Aquí, que se anunció como la primera película chilena producida especialmente para esa plataforma.

Tabla 7. La ficción de estreno en 2020 en VoD: países de origen

\begin{tabular}{|l|c|c|}
\hline \multicolumn{1}{|c|}{ País } & Títulos & $\mathbf{\%}$ \\
\hline NACIONAL (total) & $\mathbf{4}$ & $\mathbf{6 \%}$ \\
\hline PAÍSES OBITEL (total) & $\mathbf{6 0}$ & $\mathbf{9 4 \%}$ \\
\hline Argentina & 3 & $5 \%$ \\
\hline Brasil & 7 & $11 \%$ \\
\hline Chile & 2 & $3 \%$ \\
\hline Colombia & 7 & $11 \%$ \\
\hline Ecuador & 0 & $0 \%$ \\
\hline España & 16 & $25 \%$ \\
\hline EE.UU. Hispanos & 5 & $8 \%$ \\
\hline México & 18 & $28 \%$ \\
\hline Perú & 0 & $0 \%$ \\
\hline Portugal & 0 & $0 \%$ \\
\hline Uruguay & 0 & $0 \%$ \\
\hline Venezuela & 0 & $0 \%$ \\
\hline COPRODUCCIONES (Totales) & 6 & $9 \%$ \\
\hline Coproducciones Nacionales & 2 & $3 \%$ \\
\hline Coproducciones Países Obitel & 4 & $6 \%$ \\
\hline TOTAL & $\mathbf{6 4}$ & $\mathbf{1 0 0 \%}$ \\
\hline
\end{tabular}


En un plano distinto a la ficción televisiva, la pandemia les deparó a las plataformas un rol no previsto: no competir, sino sustituir a las salas de cine. El cierre de las salas de cine provocó que decenas de películas que debían estrenarse no pudieran hacerlo. Al primer momento de desconcierto le siguió el reconocimiento de que los cierres serían por un largo tiempo. Las distribuidoras y salas de cine se vieron en la necesidad de mecanismos que les permitiera mantener funcionando a la industria y encontrar un sustituto de la venta de tickets, Asimismo, hallar un modo en que los creadores estrenar sus obras ya terminadas. Con este fin, se crearon plataformas distintas a las de suscripción y que su modelo de negocio se basara en el cobro por ver. En Chile, este rol lo cumplieron Cining y Punto Play, donde fueron estrenadas las siguientes 34 películas, ante la imposibilidad de su estreno en sala: Algunas Bestias, Álvaro: Rockstars Don't Wet the Bed, Amukan, Camila Moreno: Pangea, Consuegros, Distancia Social, El Agente Topo, El Negro, El Origen del Cielo, El Príncipe, El Sabio de la Tribu, El Viaje Espacial, El Viejo del Poncho, Enigma, Esto es Spitfire!, Harley Queen, Haydee y el Pez Volador, Historia de mi Nombre, La Casa, La Cordillera de los Sueños, Lina de Lima, Los Jaivas: Todos Juntos, Matar a Pinochet, Mientes, Mi Norte es el Sur, Nona. Si Me Mojan, Yo los Quemo, Nunca Subi El Provincia, Parío y Críao, Piola, Santiago - Italia, Sobre los Muertos, Sumergida, Tengo Miedo Torero, Vendrá la Muerte y Tendrá tus Ojos. Aunque estos títulos no corresponden a ficción seriada, su aparición forzada es parte del cambio de la relación del público con en VoD.

\section{Ficción y participación de las audiencias en entornos digitales}

Desde mediados de la década de los 90 y hasta la primera década de este siglo, las telenovelas del canal público, TVN, lideraron la audiencia y son recordadas por quienes durante esos años se reunían en familia frente al televisor, luego de los estudios o al volver del trabajo. Tal vez fueron los últimos años en que las telenovelas 
cumplieron, además, con una función horaria en las jornadas de los telespectadores chilenos. Las precedían programas magazine que preparaban a la audiencia para ir "cerrando el día" y, las telenovelas a su vez, entregaban a los noticiarios centrales las audiencias más altas de la jornada. Durante la pandemia, la reposición de varias de estas producciones no se restringió a la señal de libre recepción, analógica y digital, sino que también fue una estrategia en las plataformas web de las estaciones. Televisión Nacional de Chile aprovechó la oportunidad para hacer disponible una docena de títulos de aquella época: Oro Verde (1997), Estúpido Cupido (1994), Romané (2000), Rompecorazón (1994), La Fiera (1999), Amores de Mercado (2001), El Circo de las Montini (2002) y Cómplices (2006), entre otras (El Contraste, 2021). En 2017, la estación pública inició un canal en YouTube llamado Teleseries y series / TVN, que a la fecha de este informe contaba con más de 751 millones de visualizaciones en total. No se trata de una iniciativa exclusiva y surgida a partir de la situación de pandemia, y al contar el número de interacciones generadas por el propio canal en la sección Comunidad, se puede asumir que no responde a una estrategia orgánica para alcanzar nuevas audiencias y vincularse con ellas: entre 2017 y 2019 hubo sólo 17 mensajes dirigidos a los suscriptores del canal de YouTube. En todo caso, los once mensajes publicados el año pasado anunciando los nuevos títulos publicados en el canal, duplican la frecuencia de los años anteriores. Las series y telenovelas están organizadas por playlist, aunque también el acceso a los videos puede ser unitariamente, lo que se facilita por una nomenclatura que incluye el título, el número de episodio y su título y el año. Visualmente, esta información también se incluye en la imagen del thumbnail.

El resto de los canales de televisión abierta en Chile no cuentan con un canal exclusivo de YouTube para su producción de ficción. Si bien es posible acceder a algunos títulos, éstos se mezclan con selecciones de otros programas, como las franjas matinales y programas de humor. Es el caso de Mega, aunque a diferencia de 
TVN, su canal de YouTube presenta una mayor interacción con su audiencia en la sección Comunidad. En ella hace continuos llamados a suscribirse y a promocionar contenido exclusivo para sus miembros. De igual manera que TVN, los thumbnails de los videos del canal de YouTube de Mega cuentan con un diseño que destaca el isotipo de la telenovela y tipográficamente el número del capítulo. Ambos ocupan un tercio de la imagen, en lo que se desprende la estrategia del canal de promover el acceso a su contenido de ficción online mediante la sección Home o Videos.

El caso de los canales restantes de televisión abierta con cobertura nacional es distinto. Aunque tienen una cuenta en YouTube, el uso para contenido de ficción es solamente promocional para este contenido. En el caso de Chilevisión, sólo hay acceso a ciertos programas basados en franquicias como La divina comida o Yo soy Chile. En cambio, Canal 13 incluye afiches promocionando la nueva telenovela nocturna y cuenta con un canal propio dedicado al archivo de producción de la estación, llamado RecTV, en el que sólo se encuentran segmentos de alguna telenovela antigua. No obstante lo anterior, como se da también en otros países, es posible acceder al contenido de ficción nacional a través de cuentas individuales de usuarios que no están vinculadas a las casas productoras o a los canales titulares de los derechos.

\section{Lo más destacado del año}

La elección de Historias de Cuarentena como lo más destacado del año se basa en que se trata de una producción ideada y producida en el contexto de pandemia que marcó 2020, y que al mismo tiempo logró instalarse como uno de los 10 títulos más visto del año.

Para realizar el análisis de Historias de Cuarentena se realizó un análisis narratológico de la telenovela, además de entrevistas con 
cinco agentes televisivos vinculados a su realización. Sus nombres y trayectorias se detallan en la tabla siguiente.

\begin{tabular}{|l|l|l|}
\hline NOMBRE & $\begin{array}{l}\text { CARGO EN } \\
\text { Historias de Cuarentena }\end{array}$ & ROL EN LA INDUSTRIA TELEVISIVA \\
\hline Daniela De Micheli & Productora ejecutiva & $\begin{array}{l}\text { Productora de gran trayectoria, destaca por su } \\
\text { trabajo en La Fiera y Papá a la deriva, entre otras. }\end{array}$ \\
\hline Nicolás Alemparte & Director principal & $\begin{array}{l}\text { Director de varias telenovelas como Aquí Mando Yo } \\
\text { yerdona Nuestros Pecados, entre otras. }\end{array}$ \\
\hline María Eugenia Rencoret & Directora general del Área \\
& Dramática de MEGA & $\begin{array}{l}\text { Directora y Ejecutiva a cargo tanto del Área } \\
\text { Dramática de Mega como TVN. Destaca su trabajo } \\
\text { en Amores de Mercado, y Vuelve Temprano, entre } \\
\text { tras. }\end{array}$ \\
\hline Rodrigo Cuevas & Jefe de guión & Guionista de éxitos como Los 80 y Sres. Papis. \\
\hline José Fonseca & Co-guionista & $\begin{array}{l}\text { Guionista de telenovelas en Canal 13, TVN, } \\
\text { Chilevisión y Mega, donde destacan Isla Paraíso y } \\
\text { Yo Soy Lorenzo. }\end{array}$ \\
\hline
\end{tabular}

La idea de Rodrigo Cuevas nació determinada por las condiciones de producción en la realidad de crisis por la pandemia, y se gestó de algo más bien intuitivo. "Estábamos partiendo con la crisis sanitaria, con la cuarentena en marzo y la verdad es que me empecé a sentir un poquito ansioso en términos creativos. Estaba trabajando en una teleserie para ser emitida el 2021, entonces la sensación de desconexión con la realidad me empezó a pesar. En ese contexto, pensando "qué se podía hacer" con la circunstancia que estábamos viviendo fue como llegué a esta idea". Además, fue gracias a la pandemia que este tipo de producto novedoso logró ser emitido, pues

Había una necesidad muy grande como área de sentir que podíamos ser un aporte en este contexto, de poder seguir generando contenido así que se metió por esa rendija este proyecto que seguramente de otra manera, jamás se habría podido emitir por televisión abierta. (Cuevas, 2020) 
Pese a que María Eugenia Rencoret sostiene que Historias de Cuarentena nació desde la necesidad de mantener la conexión con la audiencia en "sus emociones en [esos] difíciles momentos, enfocando el contenido en la contingencia, donde la profundidad de los diálogos [era] la protagonista absoluta", Daniela de Micheli especificó una necesidad concreta y práctica, de "hacer algún contenido nuevo, para Mega, contemporáneo, que en el fondo identificara a la gente".

El argumento se estructuró rápidamente y el proyecto nació con "una vocación de contingencia", más que en base a una gran historia de amor. Esto implicó eliminar la cohesión en torno a la historia de amor, que se desarrolló de manera muy superficial, y los personajes secundarios no solo no estaban conectados entre sí, sino que tampoco se aunaban en torno a la historia de amor de los protagonistas.

Lo más importante era que todas las historias "estuvieran ligadas en un porcentaje importante a la pandemia, independiente que después uno encontrara conflictos adyacentes a lo que fuese exactamente la pandemia" (Alemparte, 2020). Así, las tramas, normalmente definidas a priori se tuvieron que elaborar durante la marcha, pues si bien había un argumento concreto que tenía que ver con ciertos personajes, por otro lado se basaron, "explícitamente [en] los hechos noticiosos, con el apoyo de investigación periodística" para desarrollar las historias.

Además, si bien una telenovela normalmente tiene entre 90 y 120 capítulos escritos, que se emiten según decisiones de programación, en Historias de Cuarentena se desarrollaron tan solo 36 capítulos, emitidos entre el 20 de abril y el 1 de julio. Esto implicó que el arco dramático de la efímera historia de amor se desarrollara de manera más expedita y con pocos conflictos, donde la distancia y el confinamiento eran los principales antagonistas más que un villano o villana.

Lo anterior se refleja al desglosar los 36 capítulos. En los primeros doce capítulos se plantean temáticas que se veían en el 
mundo y particularmente en Chile desde marzo como el impacto sicológico de la cuarentena (Pizarro, 2020), la violencia intrafamiliar (Gámez, 2020), la tercera edad (Azaret, 2020) y las crisis de parejas (Pais, 2020).

Fueron muy, muy determinantes, muy decisivos al momento de crear los personajes y la ficción en general (...) Además de los personajes que tuvimos inicialmente fuimos incorporando algunos que nos permitieron también darle cabida a otros temas que estaban apareciendo. (Cuevas, 2020)

Lo anterior se refleja la segunda parte de los capítulos donde vemos el cierre de historias de personajes secundarios para dar paso a temáticas con una nueva pareja. También se cierra la historia de una mujer que denuncia a su esposo por violencia intrafamiliar.

La tercera parte plantea quiebres más emotivos y vinculados a la historia de amor, en la que la pareja protagónica vislumbra una posible cita cuando el encierro se termine, finalizando con una nota de esperanza.

Cabe destacar que la pandemia no afectó solo el ámbito de creación y narrativa, sino también la forma de producción. Las grabaciones eran

Muy encima del aire, porque necesitábamos que la realidad nos nutriera de historias (...) Para que los personajes estén lo más pegados a la realidad posible. (Alemparte, 2020)

Además, las grabaciones se hicieron vía Zoom, con los actores grabando desde espacios de su casa, para luego ser entregados para su edición. 
En un principio me hice cargo de todo lo que era la parte técnica, de cómo lo podíamos hacer, cómo lo íbamos a grabar, en qué formato lo íbamos a grabar y cómo iba a ser la transmisión (...) No solo se graba, se edita, se musicaliza... y todo eso, más o menos, lo mismo que se hace en una teleserie, había que llevarlo a Historias de Cuarentena. (Alemparte, 2020).

\section{Tema del año: La Ficción en tiempos de pandemia en Chile ${ }^{12}$}

Desde que la crisis sanitaria irrumpió en Chile, la pandemia resonó en distintos ámbitos y el distanciamiento social implicó el cierre de numerosos espacios, organizaciones y entidades con el fin de evitar contagios. La industria de la televisión chilena se vio particularmente afectada, no solo ante la imposibilidad de conectar físicamente a los actores y actrices, sino porque además, debido al aforo reducido, no hubo forma de juntar al equipo necesario para grabar y producir el contenido, sin contar las limitantes que implicó para los guionistas en términos de creación y escritura. Los estudios del Área Dramática del canal más activo en creación de ficción (Mega) detuvieron sus grabaciones a partir del 18 de marzo, dejando telenovelas sin finales, como fue el caso de Yo Soy Lorenzo, o cesando de las grabaciones por un tiempo indefinido, como sucedió con Verdades Ocultas.

Fue así como la ficción en Chile entró en crisis, afectando al producto audiovisual más importante de América Latina: la telenovela. Mientras la pantalla chilena se llenaba de reemisiones de antiguas telenovelas y producciones extranjeras enlatadas, productos nuevos escaseaban. Durante el 2020, se reemitieron 31 producciones nacionales (incluyendo telenovelas, series y unitarios), algunas con más de 15 años de antigüedad, y 11 extranjeras. Las telenovelas siguieron siendo

12 La información fue obtenida a partir de entrevistas con personas que trabajan en el área de producción, guion, dirección y actuación de telenovelas. Sus nombres no son incluidos a solicitud de ellos. 
lo más visto dentro de la parrilla programática (Reyes, 2020) y varios referentes de la industria lo atribuyeron a la necesidad de la audiencia de refugiarse en historias conocidas, que les permitieran distraerse en un momento de incertidumbre y angustia (Tapia y Reyes, 2020).

Sin embargo, la falta de contenido novedoso se notaba.

Esto resultó en la creación de una telenovela con explícita relación con la realidad y el acontecer noticioso en todos los niveles de producción de una telenovela: Historias de Cuarentena: psicología online.

La escasez de contenido nuevo y una parrilla programática que consumía rápidamente todos los contenidos que se programaban implicó acelerar un proceso creativo que normalmente demora meses y que culmina en la creación de una "biblia" en base a un argumento estructurado en torno a una historia de amor (Sepúlveda, 2003). Esto cambió en Historias de Cuarentena, y el eje del argumento de una telenovela que normalmente se conforma por cuatro matrices del melodrama clásico - deseo/impedimento, interclases, desconocimiento/reconocimiento, civilización/barbarie (Fuenzalida, Corro \& Mujica, 2009) - fue obviado para crear un producto híbrido entre serie y telenovela.

Posteriormente, cuando las medidas sanitarias se relajaron un poco, se reinició la grabación de nuevos estrenos como Demente, que había sido escrita el 2019, y Edificio Corona, una telenovela con toques de comedia que ocurre en un edificio durante la pandemia.

Para proteger a los trabajadores de la televisión se han implementado protocolos que incluyen la realización de exámenes para detectar el COVID-19 (PCR) cada 72 horas, toma de temperatura durante las jornadas de grabación y entrega de mascarilla al llegar con recambio durante el día; dispensadores de alcohol gel y todos los ensayos son con mascarilla, sólo se sacan al momento al grabar. Estos procedimientos son llevados adelante por personal médico que está siempre presente. 
Se han instituido aforos máximos en los vestuarios, maquillaje y peluquería para permitir distancia social. Las personas que trabajan en esta área usan mascarillas y otros accesorios especiales para evitar contacto directo. Además, cada actor tiene su propio estuche de maquillaje y otros materiales que no se mezclan con los de otros.

Los sets son sanitizados con frecuencia. En esos momentos, además se ventila y todas las personas del equipo salen y vuelven a pasar por los procedimientos de higienización antes de retornar.

$\mathrm{Si}$ bien todos estos procedimientos han implicado gastos de tiempo, los entrevistados coinciden en que se han internalizado adecuadamente y ha sido posible trabajar en los tiempos esperados. Los horarios de grabación se han hecho más breves, también para evitar contactos demasiado extensos.

En general, los entrevistados valoran positivamente la implementación de estos procedimientos. Se sienten seguros y, por lo mismo, están dispuestos a seguir adelante pese a todo. Esto, además, considerando un entorno de inestabilidad económica de los trabajadores de la cultura, que se han visto particularmente golpeados por las limitaciones impuestas por la pandemia.

Desde el punto de vista del desarrollo de la ficción audiovisual, los protocolos han implicado cambios relativamente menores. Las escenas de besos o más íntimas han disminuido al mínimo. Solo se graban aquellas que son esenciales para el avance de la trama y se programan al día siguiente de la realización de los exámenes médicos preventivos. Algo similar pasa con las escenas masivas. También se ha limitado la cantidad de exteriores y las grabaciones nocturnas por los reglamentos de cuarentena y toque de queda implementados en distintas comunas de la ciudad.

Esto ha implicado que se haya debido solicitar cambios en los guiones, porque lo escrito no se puede grabar, porque no hay autorización. Algunos entrevistados evaluaron esto como menor y otros como muy complejo. Sin embargo, todos evalúan que los trabajos han sido 
bien recibidos por el público lo que estaría reflejado en los niveles de audiencia.

Este éxito lo atribuyen, en parte, a la capacidad de recoger la realidad y las dificultades que ha provocado la pandemia en la ficción. En el caso de Edificio Corona, esto se ha hecho incorporando momentos de ternura y comedia, además de los temores asociados a este contexto.

Hasta el momento de la escritura de este artículo no se han reportado casos de COVID-19 relacionados con grabaciones. 


\section{Referencias}

24H. (2020). Chilenos se unen a los aplausos en el mundo para los profesionales de la salud. 24horas online, vía https://www.24horas. cl/nacional/chilenos-se-unen-a-los-aplausos-en-el-mundo-paralos-profesionales-de-la-salud-4035300

AAM (2021). Informe de inversión publicitaria de la Asociación de Agencias de Medios, diciembre 2020. https://aam.cl/wp-content/ uploads/2021/01/Informe-Inversio\%CC\%81n-en-Medios_Diciembre_2020_AAM_env.pdf

ACHAP (2012). Inversión publicitaria 2011. https://www.achap.cl/wpcontent/uploads/2017/05/Inversion2011.pdf

Alemparte, N. (2020). Entrevista personal al Director principal de Historias de Cuarentena.

Azaret, M. (2020) ¿Eres mayor de 60 o tienes un familiar de alto riesgo? Hablamos del miedo, irritabilidad y aislamiento que viven los más afectados. CNN. Online, vía https://cnnespanol.cnn. com/video/covid-19-pandemia-coronavirus-azaret-vivelasaludancianos-estres/

CNTV (2019) Adultos mayores y televisión.

https://www.cntv.cl/wp-content/uploads/2020/10/adultos mayores_y_tv_2_pdf

Cuevas, R. (2020). Entrevista personal al Jefe de Guión y creador de la idea original de Historias de Cuarentena.

De Micheli, D. (2020). Entrevista personal a la Productora Ejecutiva de Historias de Cuarentena. 
El Contraste (2021). Para la cuarentena: 12 exitosas telenovelas chilenas que puedes ver en YouTube. https://elcontraste.cl/para-lacuarentena-12-exitosas-telenovelas-chilenas-que-puedes-ver-enyoutube $/ 23 / 03 / 2020 /$

Equipo El Repuertero (2020) ¿Lo viste? Asi fue el exitoso primer capítulo de Historias en Cuarentena. Rescatado de http://www.elrepuertero.cl/noticia/tecnologia/lo-viste-asi-fue-el-exitoso-primer-capitulo-de-historias-en-cuarentena

Fonseca, J. (2020). Entrevista personal al guionista secundario de Historias de Cuarentena.

Fuenzalida, V.; Corro, P., y Mujica, C. (2009). Melodrama, Subjetividad e Historia: En el Cine y Televisión chilenos de los 90. Santiago, Chile. Gráfica LOM.

Gámez, N. (2020). Cuarentena: aunque la padezcan, menos mujeres denuncian violencia. Online, vía http://concriterio.gt/cuarentenaaunque-la-padezcan-menos-mujeres-denuncian-violencia/

Meganoticias. (2020) Historias de Cuarentena: Primera serie remota sobre coronavirus debuta el lunes 20 de abril. Rescatado de: www. Meganoticias.cl/tendencias/298563-historias-de-cuarentena-debut-teleserie-serie-Mega-fecha-actores-elenco.html

Pais, A., (2020). Coronavirus: 6 consejos para pasar el aislamiento con tu pareja (sin terminar separados). BBC Onlie, vía https://www. bbc.com/mundo/noticias-52036372

Palma, S., \& Pizarro, C. (2020) "El estallido del hambre": Dirigentes y vecinos de El Bosque explican las razones de la nueva crisis social. El Desconcierto Online vía https://www.eldesconcierto. cl/2020/05/19/el-estallido-del-hambre-dirigentes-y-vecinos-deel-bosque-explican-las-razones-de-la-nueva-crisis-social/ 
Pizarro, J.C. (2020). Efectos no deseados El impacto psicológico de la cuarentena. Diario el Día. Disponible vía http://www.diarioeldia. cl/region/impacto-psicologico-cuarentena

Rencoret, M.E. (2020). Entrevista personal a la directora general del Área Dramática de MEGA, a cargo de la estructuración y creación de "Historias de Cuarentena.

Reyes, P. (Abril 2020). Entre grabaciones paralizadas e historias en receso: teleseries chilenas enfrentan una total incertidumbre. La Tercera Online vía https://www.latercera.com/entretencion/noticia/ entre-grabaciones-paralizadas-e-historias-en-receso-teleserieschilenas-enfrentan-una-total-incertidumbre/AKKNSVWJS5EBPIBJAYBQBD6GEQ/

Reyes, P. (Mayo 2020). Teleseries se alzan entre lo más visto por los chilenos durante la cuarentena. La Tercera Online vía https://www. latercera.com/entretencion/noticia/teleseries-se-alzan-entre-lomas-visto-por-los-chilenos-durante-la-cuarentena/MVRBNHIORJFL5MVR4J4MM6H7IA/

Sepúlveda, F. D. (2003) Análisis y evolución del guión en las teleseries chilenas. Tesis para optar al Título de Periodista y al grado de Licenciado en Comunicación Social. Universidad Austral de Chile.

Subtel (2021a). Serie estadística: suscriptores de televisión de pago. https://www.subtel.gob.cl/wp

content/uploads/2021/04/1_SERIES_SERVICIOS_LIMITADOS_TV_ DIC20_030321.xlsx

Subtel (2021b). Serie estadística: servicio de acceso a internet fija.

https://www.subtel.gob.cl/wpcontent/uploads/2021/04/1_ SERIES_CONEXIONES_INTERNET_FIJA_DIC20_030321. xlsx 
Subtel (2021c). Serie estadística: servicio de acceso a internet móvil.

https://www.subtel.gob.cl/wp-content/uploads/2021/04/2_SERIES_CONEXIONES_INTERNET_MOVIL_DIC20_030321. xlsx

Subtel (2021d). Serie estadística: tráfico de datos fijos.

https://www.subtel.gob.cl/wp-content/uploads/2021/04/3 SERIES_TRAFICO_DATOS_FIJOS_DIC20_030321.xlsx

Tapia C. y Reyes P. (Agosto 2020) Por qué las audiencias se han refugiado en las teleseries clásicas en Chile y Latinoamérica para resistir el encierro. La Tercera Online vía https://www.latercera.com/ entretencion/noticia/por-que-la-audiencia-se-ha-refugiado-enlas-teleseries-clasicas-en-chile-y-latinoamerica-para-resistir-elencierro/BBBMMI3DIVEGRDB73KUNIVLRLI/ 